\title{
Fuzzy Controlled THD Reduction and Performance Improvement of a PMBLDC Motor Using MMLI
}

\author{
Karuppanasamy CHANDRASEKARAN*, Rajendran ARTHANARI
}

\begin{abstract}
In this study, an improved chopper is implemented for current extraction, enhanced solar power generation control, and increased voltage. A simplified space vector control technique is applied to operate the permanent-magnet brushless DC drive (PMBLDC) by controlling the inverter operation. This is used as a special electrical machine with reliable operation and maintenance control. This system uses the Perturb and observer (P\&O) algorithm which maximises the PV-system output power and reduces the overall cost. A fuzzy logic controller (FLC) is used to control the duty cycle and increase the PV voltage. The modified multilevel inverter (MMLI) reduces harmonic distortions and low-switching losses by using a self-tuning filter (STF). This study achieved a better PMBLDC system performance, an improved efficiency, and eliminated the total harmonic distortion (THD) by the self-tuning filter with and without using MATLAB/SIMULINK.
\end{abstract}

Keywords: Active Power Filter; Boost converter; Fuzzy logic controller; Maximum Power Point Tracking; Multilevel Inverter; Permanent Magnet Brushless DC Drive; photovoltaic array; Self-Tuning Filter

\section{INTRODUCTION}

The photovoltaic framework as a sustainable power source is popular in several countries. In this systems sun oriented vitality becomes significant for the vitality supply. PV clusters (19) generate power from sunlight and its different parts transform, disperse, and store the vitality delivered by the framework. Sun-oriented vitality is utilised by charging batteries for different applications. A sun-oriented PV [1, 7-10] exhibits generated power by accomplishing MPPT calculations that utilises a DC-DC converter [18, 20]. The chopper converter (support converter) [6] is used to increase the info voltage. The essential information voltage is low and yield voltage is high. The aim of this study is to make a chopper circuit with an info voltage of $12 \mathrm{~V}$ and yield voltage of $24 \mathrm{~V}$.

The motivation behind innovating fuzzy logic controllers (FLCs) $[2,5]$ was to control engine drives. In this study, an FLC controls the obligation cycle and builds up the voltage. The FLC can effectively deal with heap contrasts and disturbances on the grounds where the controller is used. Brushless DC (BLDC) engines [5, 7-9] are synchronous engines with perpetual magnets on the rotor and an armature twisting on the stator. It can operate rapidly under different conditions. It has an advanced engine that provides a huge torque and requires low maintenance because of the annihilation of a mechanical commutator. The inverter switches the scaffold $\mathrm{ON}$ and OFF to ensure a current flow in separate loops. The separate loops depend upon the data of the appropriate commutator, engine pivot, and rotor position. In the rotor structure, windings were placed at the core of the motor. The rotor magnets are used as a covert o dissipates the heat from the motor. One of the advantages of a staggered inverter is their low yield voltage e that results in a high yield quality, low consonant segment, easy calculability, and low exchanging misfortunes. Therefore, in this frame work we chose a sun-powered PV, DC-DC converter [15], PMBLDC [15], and an adjusted staggered inverter which can operate in load and barometric conditions. A MATLAB/SIMULINK is utilized to confirm the exhibition of the PMBLDC engine utilizing high advance up adjusted multi-inverter. In Existing systems have high ripple (THD) and more switching loss. The challenges of the paper are sorted out as follows: in area 2 is clarifies the difficult plan; in segment 3 depicted the framework arrangement and rule of activity; in segment 4 clarifies the structure of PMBLDC engine utilizing high advance up altered multi-inverter; Results has been talked about in segment 5 and segment 6 at last closes the paper.

\section{PROBLEM FORMULATION}

The aim of this paper is to propose a PMBLDC motor using the high step up the modified multi-level inverter. To Design of proper various control system parameters, maximum power point tracking (MPPT) and FLC technique used for Solar power generation. An effective photovoltaic system to achieve without loss and the analysis of PMBLDC motors are made with the boost converter, interleaved boost converter with Fuzzy logic control circuit and MPPT. The boost converter interleaved with PMBLDC Drive the modified multi-level inverter and self-tuning filter to eliminate harmonics. This paper presents how reducing harmonics is achieved to the new topology of modified multilevel inverter. In order to achieve the better system performance, efficiency and reliability by Brushless DC motor.

\section{SYSTEM CONFIGURATION AND PRINCIPLES OF OPERATION}

In this proposed work, a solar array fed Chopper i.e. Boost converter which is used to increase level of voltage. The DC - DC converter is to increase the PV voltage and balance the current level. Fuzzy logic is utilized to control the duty cycle and to increase the voltage. The MMLI has been used for adjustable speed drives, to eliminate harmonics and high or medium power system because of static reactive power compensation. Hall effect sensor is to control speed and position of the PMBLDC. In this PMBLDC motor using the high step up [6] the modified multi-level inverter (MMLI) system achieve better system performance, improve PMBLDC motor efficiency and to eliminate harmonics using self-tuning filter [2]. Fig. 1 
shows the block diagram of PMBLDC Motor using a high step up MMLI with STF filter.

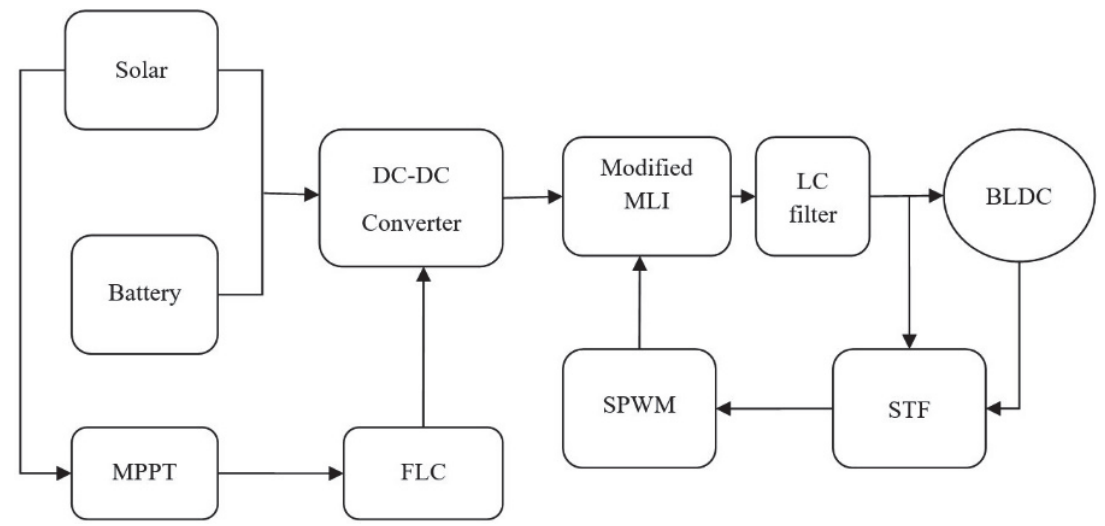

Figure 1 PMBLDC Motor Using High Step up Modified Multi-inverter Block Diagram

\section{DESIGN OF PMBLDC MOTOR USING HIGH STEP UP MODIFIED MULTI-INVERTER}

In the Fig. 2 shows the simulation for PMBLDC Motor using a high step up modified multi-inverter. This simulation consists of PMBLDC motor, Solar PV, Battery, DC-DC Converter, SPWM, MMLI, FLC, STF and Hall Effect sensor.

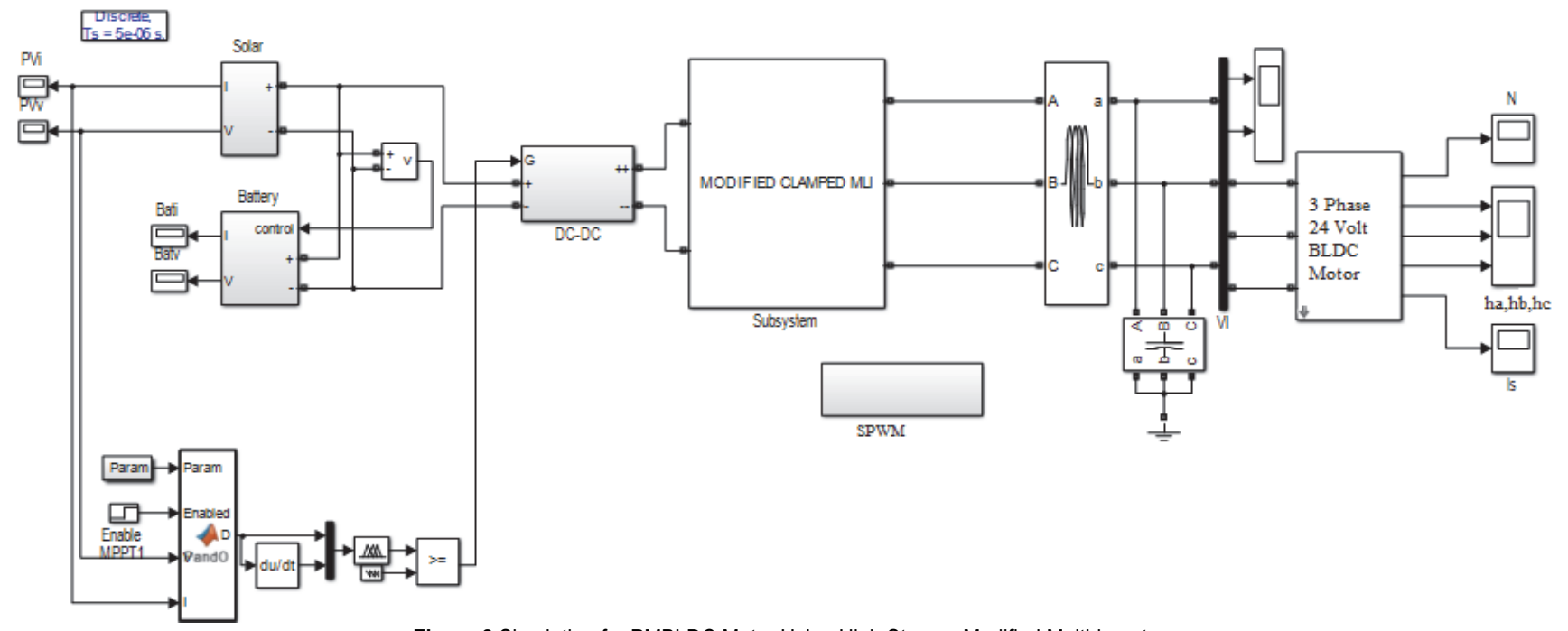

Figure 2 Simulation for PMBLDC Motor Using High Step up Modified Multi-inverter

\subsection{Maximum Power Point Tracker}

Maximum power point tracking methodology is adopted for extracting maximum power from the PV module. The process is implemented by varying the duty cycle of DC to DC convertor [5]. The energy is extracted in the greatest possible way from the PV module clusters. The most effective voltage is obtained from the maximum point tracked in the PV module. To obtain this Perturb and Observance $(\mathrm{P} \& \mathrm{O})$ algorithm is adopted $[10,16]$. In this proposed technique, if the battery framework input voltage is not exactly the yield voltage so help converter ought to be picked for MPPT [26] P\&O (Perturb and Observer) calculation. In the Fig. 3 shows the $\mathrm{P} \& \mathrm{O}$ calculation flowchart.

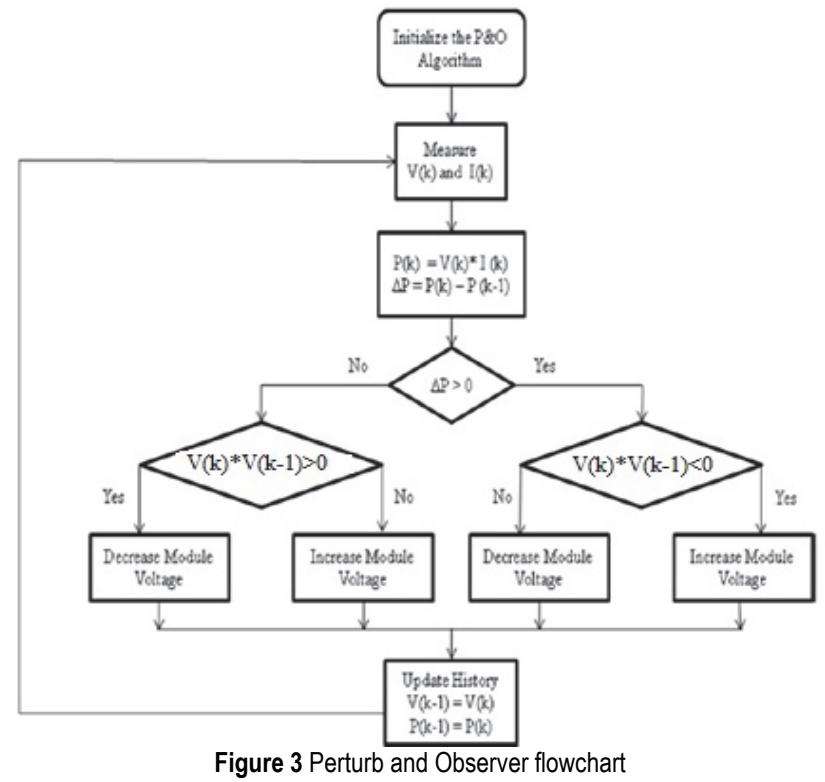


$\mathrm{P} \& \mathrm{O}$ calculation causes the intensity of the sunoriented PV [16] cluster to change continually and if the force increments because of annoyance. After that irritation is preceded a similar way then the force diminishes after that pinnacle power is reached and after that bother turns around. The calculation vacillates around the pinnacle moment that the consistent state is reached.

\subsection{DC - DC Converter (Boost Converter)}

PMBLDC requires $24 \mathrm{~V}$ for its operation so the voltage obtained from the battery is not sufficient. In our application, the voltage obtained from solar is $12 \mathrm{~V}$ so it is not enough to drive a PMBLDC motor [19-20] as it requires $24 \mathrm{~V}$ for its operation. The boost converter is constantly increasing the input voltage. So, it is known as a step-up converter.

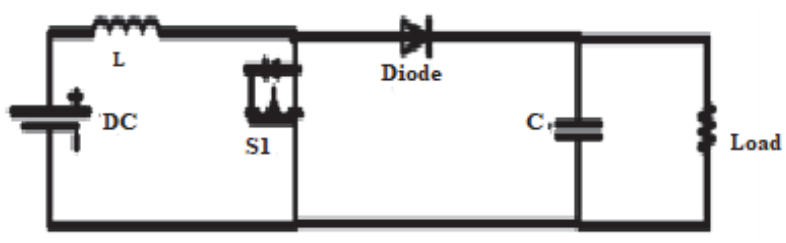

Figure 4 Boost Converter

In Fig. 3 shows the circuit diagram of the boost converter. DC converter [5] can be used as a switching diode; it converts a fixed DC voltage into variable DC voltage. In DC-DC converter [17]. Tab. 1 shows the parameters are used in the boost converter.

Table 1 Parameters used in the boost converter
\begin{tabular}{|c|c|c|}
\hline S.No & Parameters & Value \\
\hline 1 & Switching frequency $/ \mathrm{kHz}$ & 5 \\
\hline 2 & Input Voltage / V & 12 \\
\hline 3 & Inductance / $\mathrm{mh}$ & 0.12 \\
\hline 4 & Capacitor $/ \mathrm{mf}$ & 4.55 \\
\hline 5 & Load Resistance / $\Omega$ & 0.96 \\
\hline
\end{tabular}

\subsection{Fuzzy Logic Controller}

Fuzzy logic [2] is capable of making effective decisions and this technique is widely applied today. To implement fuzzy logic [12] is applied to an application requires the following three steps. The first step is called fuzzification. It is changing of real values into fuzzy values. Fuzzy inference process is the second step combined the fuzzy variables with the control rules to obtain the fuzzy output. The finally is defuzzification it is reconverted fuzzy variables into real world signal.

\begin{tabular}{|c|c|c|c|c|}
\multicolumn{7}{|c|}{ Table 2 Fuzzy Rules } \\
\hline $\mathrm{d} E$ & ZE & PS & PM & PB \\
\hline PE & ZE & ZE & ZE & ZE \\
\hline PM & PS & PS & PS & PM \\
\hline P & PM & PS & PM & PM \\
\hline
\end{tabular}

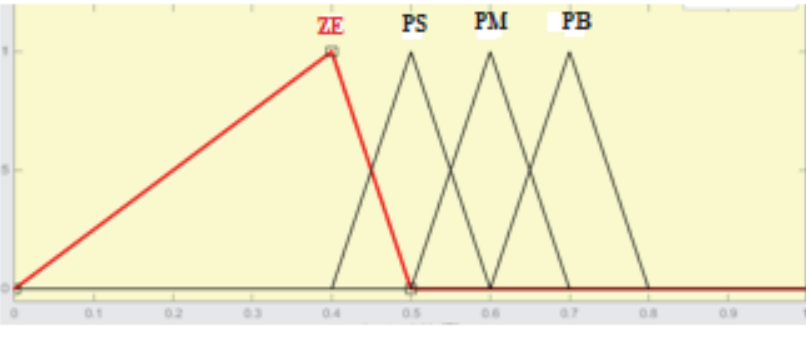

Figure 5 Fuzzy Diagrammatic Representation

The contribution to the fluffy rationale is a mistake $(E)$ and change in blunder $(\mathrm{d} E)$ and the yield obtained is the dynamic segment of current. Both $E$ and $\mathrm{d} E$ are changed from ceaseless factors to fluffy factors by utilizing four part works. The yield of the fluffy rationale controller is assessed utilizing fluffy principle appeared in Tab. 2 for four participation capacity of each info, the yield will be 16. Fluffy arrangements of a blunder and change in mistake are consolidated to create a standard for the framework. These principles are known as rule base framework. Fig. 4 shows the fluffy control rule diagrammatic portrayal.

\subsection{Modified Multilevel Inverter}

The staggered inverter [11-14] has been utilized for medium or high force framework in view of static responsive force remuneration, movable speed drives and to lessen consonant mutilation. A modified 7 level and 13 level inverter is proposed in the methodology.

An ' $n-1$ ' bearer is utilized for ' $n$ ' level SPWM inverter. SPWM utilizes triangular wave for sinusoidal reference wave structure. The reference is sine wave structure and triangular bearer wave structure utilized for staggered SPWM. Semiconductor stress is reduced with usage of multilevel inverter and thus reducing the exchanging misfortunes.

Table 3 Parameters of Multilevel Inverter

\begin{tabular}{|c|c|c|}
\hline S1 No & Parameters & Range \\
\hline 1 & $\begin{array}{c}\text { 7-level and 13-level inverters } \\
\text { Input Voltage }\end{array}$ & $24 \mathrm{~V}$ \\
\hline 2 & IGBT Frequency & $5 \mathrm{kHz}$ \\
\hline 3 & Inductor & $2 \mathrm{e}^{-3}$ \\
\hline 4 & Capacitor & $0.5 \mathrm{e}^{-6}$ \\
\hline
\end{tabular}

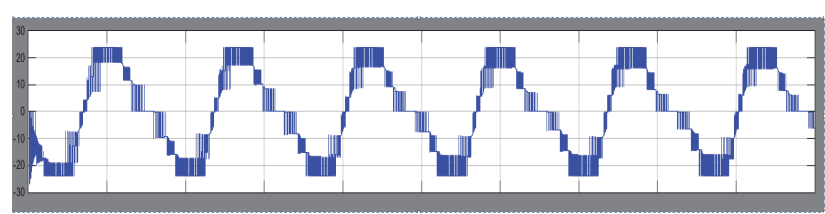

Figure 6 Re-enactment yield of 7 - level inverter

In Fig. 6 shows the recreation yield of a 7-level inverter. A 7-level inverter offers great outcomes yielded wanted 7-level yield with low complete consonant mutilation contrasted with the regular strategy.

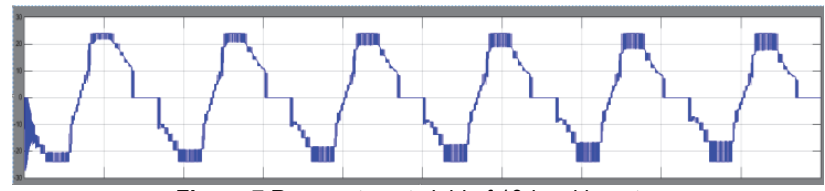

Figure $7 \mathrm{Re}$-enactment yield of 13-level inverter 
In the Fig. 7 shows the mimicked yield of the 13-level inverter. The 13-level inverter offers great outcome yielded wanted 13-level yield with exceptionally low symphonious contortion contrasted with the 7-level inverter. From the past topology made far progress in the examination.

\subsection{Self-tuning Filter}

A self-tuning channel (STF) is to supplant a low pass channel and it is an arrangement dynamic channel. The STF is to diminish the most extreme degree of symphonies end and improve the framework execution. In this proposed framework, the all out symphonies decrease could be seen with self-tuning channel. One self-tuning channel [2] is utilized to remove the essential part straightforwardly from misshaped volt and amps signals in the $\alpha-\beta$ reference outline. The PC reproductions under mutilated voltage conditions are utilized to figure the reference current age methodologies.

The transfer function equivalent of the integration in the frame SRF by:

$V_{x, y}(t)=\mathrm{e}^{-j w t} \int \mathrm{e}^{-j w t} u_{x, y}(t) \mathrm{d} t$

The instantaneous signals, Which $u_{x, y}$ and $V_{x, y}$ are respectively before and after integration in the SRF. In the Eq. (1) transfer function expressed after Laplace transformation.

$H(s)=\frac{V_{x, y}(s)}{u_{x, y}(s)}=\frac{s+j w}{s^{2}+w^{2}}$

In this paper to get $w_{c}$ so Eq. (2) becomes:

$H(s)=\frac{V_{x, y}(s)}{u_{x, y}(s)}=\frac{(s+k)+j w_{c}}{(s+k)^{2}+w_{c}^{2}}$

Where $w_{c}$ is STF with cut off frequency.

To modified the Eq. (2) and Eq. (3) by substituting the input signals $u_{x, y}(s)$ by $x_{\alpha \beta}(s)$ and the output signals $v_{x, y}(s)$ by $\hat{x}_{\alpha \beta}(s)$, Eq. (4) and Eq. (5) can be obtained.

$\hat{x}_{\alpha \beta}(s)=\frac{k}{s}\left[x_{\alpha}(s)-\hat{x}_{\alpha}(s)\right]-\frac{w_{c}}{s} \hat{x}_{\beta}(s)$

$\hat{x}_{\beta}(s)=\frac{k}{s}\left[x_{\beta}(s)-\hat{x}_{\beta}(s)\right]-\frac{w_{c}}{s} \hat{x}_{\alpha}(s)$

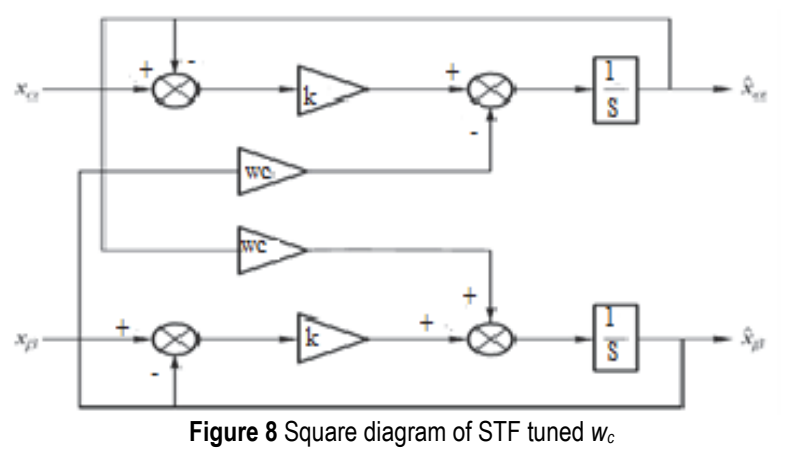

The STF tuned to the pulsation $w_{c}$ is delineated in the figure. Simultaneously as various estimations of the parameters $k$ versus the recurrence reaction of the STF. The STF can be seen that no removal is built up by this channel at the framework throb. In STF, the major part can be separated from contorted electrical signs immediately and sufficiency evolves.

The load current $i_{L a}, i_{L b}$ and $i_{L c}$ the $\alpha-\beta$ axis which transformed by the $3 \phi$ three wire system.

$\left[\begin{array}{l}i_{\alpha} \\ i_{\beta}\end{array}\right]=\sqrt{\frac{2}{3}\left[\begin{array}{ccc}1 & -\frac{1}{2} & -\frac{1}{2} \\ 0 & \frac{\sqrt{3}}{2} & -\frac{\sqrt{3}}{2}\end{array}\right]}\left[\begin{array}{l}i_{L a} \\ i_{L b} \\ i_{L c}\end{array}\right]$

Here the currents in the $\alpha-\beta$ axis can be decomposed components by:

$i_{\alpha}=\hat{i}_{\alpha}+\hat{i}_{\alpha}$

$i_{\beta}=\hat{i}_{\beta}+\hat{i}_{\beta}$

The STF removes the major segments at the throb $w_{c}$ straightforwardly from the flows in the $\alpha-\beta$ pivot. The heap flows of the $\alpha-\beta$ consonant parts are determined by deducting the STF input signals from the proportional yields. In Fig. 9 shows the square chart of STF-based symphonious isolator.

This self-tuning filter is reducing harmonics of the distorted voltages. According to this filter is to improve the harmonic isolator performance. After that evaluation of the fundamental component $\hat{v}_{\alpha \beta}$ and harmonic currents $\hat{i}_{\alpha \beta}$, the $p$ and $q$ powers are given as the Eq. (6) and Eq. (7).

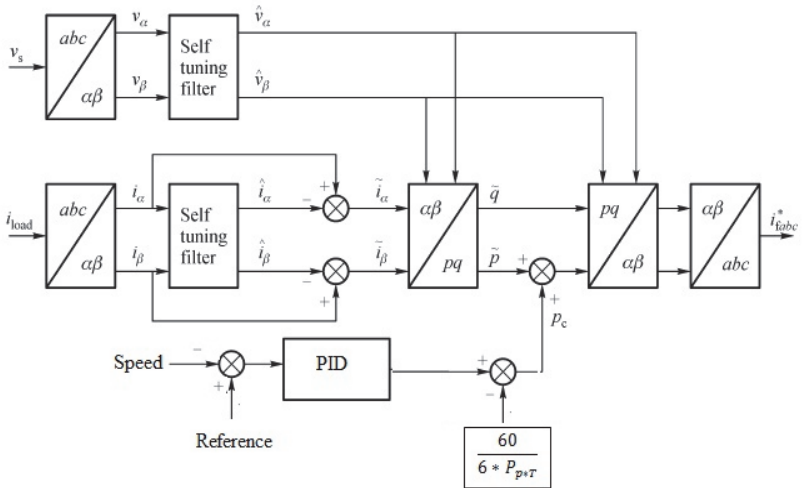

Figure 9 Square Diagram of STF-based consonant isolator

$\left[\begin{array}{l}v_{\alpha} \\ v_{\beta}\end{array}\right]=\sqrt{\frac{2}{3}\left[\begin{array}{rrr}1 & -\frac{1}{2} & -\frac{1}{2} \\ 0 & \frac{\sqrt{3}}{2} & -\frac{\sqrt{3}}{2}\end{array}\right]}\left[\begin{array}{l}v_{s a} \\ v_{s b} \\ v_{s c}\end{array}\right]$

Instantaneous active power:

$p=i_{\alpha} \hat{v}_{\alpha}+i_{\beta} \hat{v}_{\beta}$

Instantaneous reactive power: 
$q=i_{\beta} \hat{v}_{\alpha}-i_{\alpha} \hat{v}_{\beta}$

Where:

$p=\hat{p}+\hat{p}$

$q=\hat{q}+\hat{q}$

The $\alpha-\beta$ related to the power components $\hat{p}$ and $\hat{q}$ can be written as:

$\left[\begin{array}{l}\hat{p} \\ \hat{q}\end{array}\right]=\left[\begin{array}{ll}\hat{v}_{\alpha} & \hat{v}_{\beta} \\ \hat{v}_{\beta} & \hat{v}_{\alpha}\end{array}\right]\left[\begin{array}{l}\hat{i}_{\alpha} \\ \hat{i}_{\beta}\end{array}\right]$

Current references frame $i_{\alpha \beta}^{*}$ are written by:

$i_{\alpha}^{*}=\frac{\hat{v}_{\alpha}}{\hat{v}_{\alpha}^{2}+\hat{v}_{\beta}^{2}}\left(\hat{p}+p_{c}\right)-\frac{\hat{v}_{\beta}}{\hat{v}_{\alpha}^{2}+\hat{v}_{\beta}^{2}} \hat{q}$

$i_{\beta}^{*}=\frac{\hat{v}_{\beta}}{\hat{v}_{\alpha}^{2}+\hat{v}_{\beta}^{2}}\left(\hat{p}+p_{c}\right)-\frac{\hat{v}_{\alpha}}{\hat{v}_{\alpha}^{2}+\hat{v}_{\beta}^{2}} \hat{q}$ by:

Then, the filter reference currents $x-y-z$ are defined

$$
\left[\begin{array}{l}
i_{f x}^{*} \\
i_{f y}^{*} \\
i_{f z}^{*}
\end{array}\right]=\sqrt{\frac{2}{3}}\left[\begin{array}{cc}
1 & 0 \\
\frac{1}{2} & \frac{\sqrt{3}}{2} \\
-\frac{1}{2} & -\frac{\sqrt{3}}{2}
\end{array}\right]\left[\begin{array}{c}
i_{\alpha}^{*} \\
i_{\beta}^{*}
\end{array}\right]
$$

\subsection{Hall-Effect Sensors}

The Hall Effect is a perfect detecting innovation and it is an attractive field sensor so it tends to be utilized in PMBLDC engine. The Hall Effect sensor detects the attractive field and it creates an electric sign. It is that changes over the electrical sign to one that meet the prerequisite of the framework. In PMBLDC, the changeless magnet material mounted on the rotor shaft works the Hall Effect sensors. The Hall Effect sensors sense the rakish situation of the engine and feed this data into a rationale circuit. The rationale circuit encodes this data and controls switches in a drive circuit.

Fig. 9 shows the Hall Effect signal. The sensor feedback is performed by Hall- Effect sensors. At any new signal is identified, the different switching pattern is applied. The Hall Effect sensors [4, 5, 20] are located inside the motor as position sensors. The sensor feedback method used three hall sensors are fixed inside the motor.

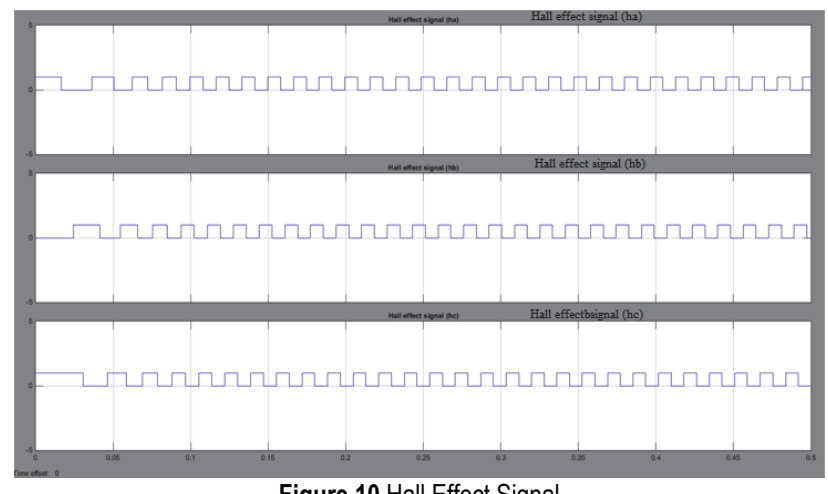

Figure 10 Hall Effect Signal

\section{SIMULATION RESULT}

A Simulation model of a Permanent BLDC engine utilizing the high advance up adjusted multi-inverter with self-tuning channel is structured utilizing MATLAB/SIMULINK apparatus. The Simulink model comprises Solar PV, Boost converter, FLC, MMLI, PMBLDC, and STF. The above Simulink model has been structured utilizing the accompanying parameters as appeared in Tab. 3 .

\begin{tabular}{|c|c|} 
Table 3 Parameters Used In Simulink Model \\
\hline Parameters & Value \\
\hline Power / Watts & 600 \\
\hline Speed / RPM & 3300 \\
\hline Poles of the motor / P & 4 \\
\hline Moment of inertia / J $\left(\mathrm{kgm}^{2}\right)$ & 0.00062 \\
\hline Voltage / V/krpm & 24 \\
\hline Torque / N-m & 1.33 \\
\hline Stator Phase Resistance / $\Omega$ & 0.09 \\
\hline
\end{tabular}

\subsection{Multilevel Sinusoidal Pulse Width Modulation}

SPWM for the MMLI based on typical two levels of the waveform i.e., triangular carrier and the sinusoidal reference waveform.

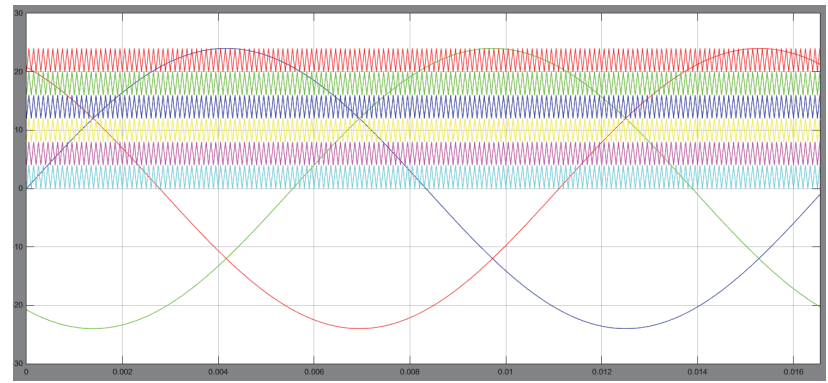

Figure 11 Reference waveform of modified MMLI using multi carrier PWM

The transporter arrangement for the bearer based SPWM method is appeared in Fig. 11 is the stage restriction mien (POD) procedure for 7-level, 6 conveys are adjusted as symmetric identical representations over the zero-reference pivot. In Fig. 10 shows the reference sine and triangular bearers of changed staggered inverter utilizing multi-transporter PWM. 


\begin{tabular}{|c|c|c|c|}
\hline IIII & III & IIIII & III \\
\hline - IIIII & IIIII & IIIII & IIIII \\
\hline 긴 & IIIIII & IIIIII & IIIII \\
\hline IIIII & IIIIII & IIIIL & IIIIII \\
\hline IIIIIII & IIIIII & IIIIII & |IIIIII \\
\hline \multicolumn{2}{|c|}{ 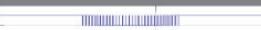 } & \multicolumn{2}{|c|}{ 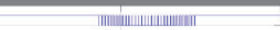 } \\
\hline
\end{tabular}

Figure 12 PWM signal for Inverter

In Fig. 12 shows the PWM signal for the inverter. The Pulse width modulation [3] output has six phases of the flight of stairs yield for 7-level inverter.

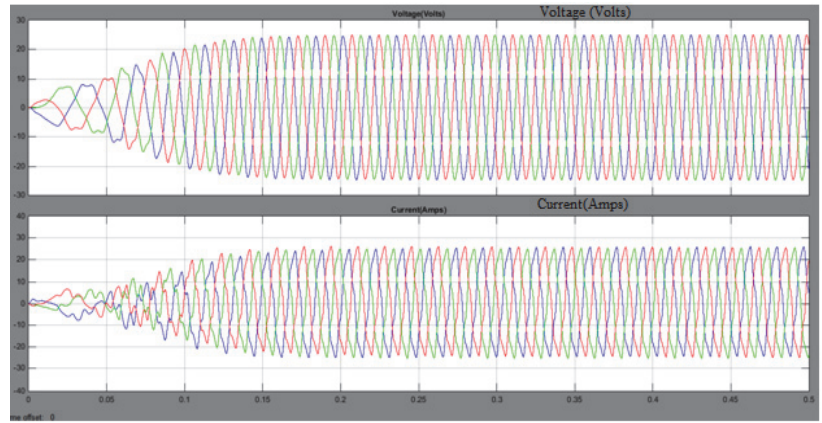

Figure 13 With Filter Output Wave Form

In Fig. 13 represents the channel yield waveform. The main distinction between two level SPWM and staggered SPWM is no. of bearers utilized. Producing a correlative pair of switches in the diode clipped in the staggered inverter is the association of specific transporter and reference is utilized.

\subsection{FFT Analysis for Without Self-Tuning Filter}

In the THD analysis voltage utilizing 13 - level inverter without channel, graph is shown in Fig. 14. The THD of the load voltage is $2.22 \%$ (supply voltage without STF).

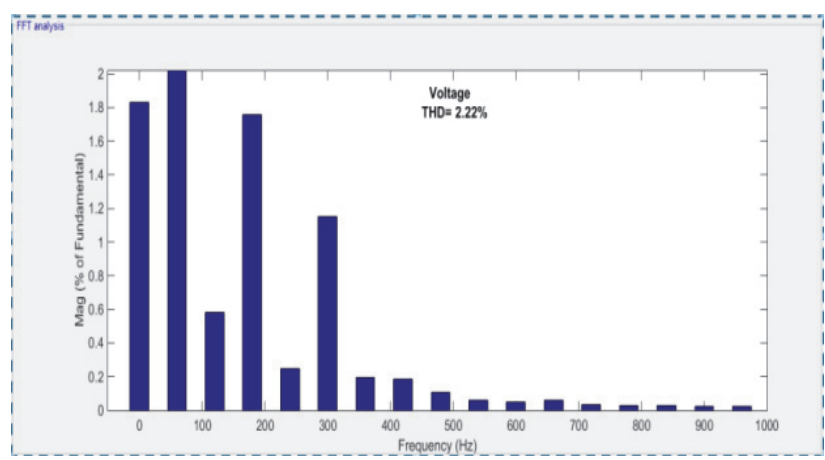

Figure 14 THD analysis voltage utilizing 13-level inverter without channel

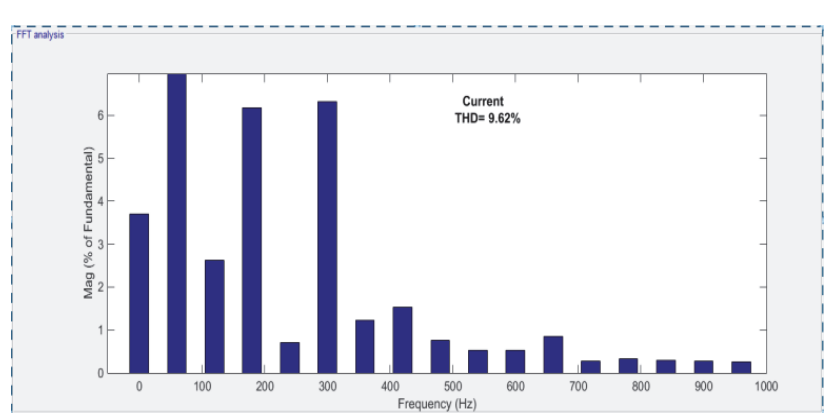

Figure 15 THD analysis current utilizing 13-level inverter without channel
In the THD analysis current utilizing 13-level inverter without channel graph is shown in Fig. 15. The THD of the load current is $9.62 \%$ without self-tuning filter.

\subsection{FFT Analysis for With Self-Tuning Filter}

In the FFT investigation of THD voltage utilizing with self-tuning channel, diagram is appeared in Fig. 16. The complete symphonious mutilation (THD) of the heap voltage is $1.53 \%$ (supply voltage with self-tuning channel).

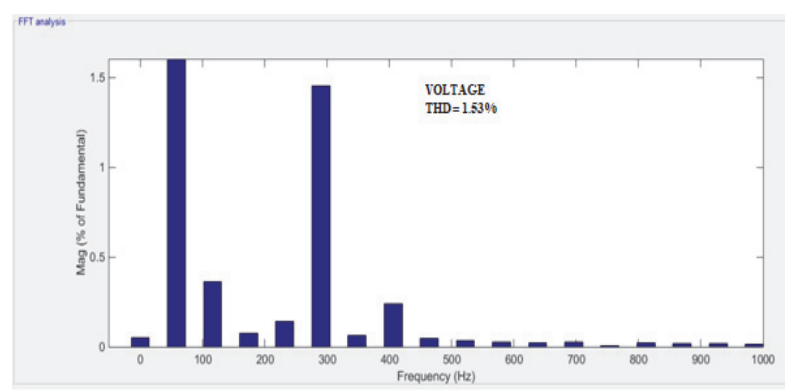

Figure 16 THD Analysis of voltage utilizing 13-level inverter with STF

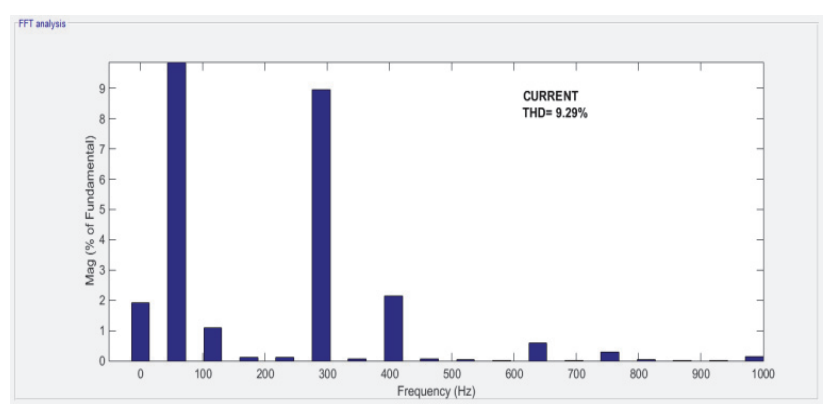

Figure 17 THD Analysis of current utilizing 13-level inverter with STF

In the analysis of THD current utilizing the13-level inverter with self-tuning filter graph is shown in Fig. 16. THD) of the load current is $9.29 \%$.

\subsection{Comparisons of Different Types of Inverter THD}

From Fig. 18 shows the examinations of the THD voltage for without channel and with channel. In the 7-level inverter absolute symphonious bending voltage for without channel is $38.77 \%$, 13-level inverter all out consonant mutilation voltage for without channel is $36.58 \%$ and 13 level inverter complete consonant contortion voltage for with channel is $2.22 \%$.From this outcome shows the more significant level inverter with channel has low symphonious twisting.

Table 4 Different types of Inverters THD Level

\begin{tabular}{|c|c|c|}
\hline Module & Topology & THD /\% \\
\hline Conventional & $\begin{array}{c}\text { A cascaded bridge 13-level } \\
\text { inverter topology }\end{array}$ & 9.14 \\
\hline Existing & $\begin{array}{c}\text { Hybrid Thirteen Level } \\
\text { Cascaded H-Bridge } \\
\text { Inverter }\end{array}$ & 8.74 \\
\hline Proposed & Modified MLI & 1.53 \\
\hline
\end{tabular}



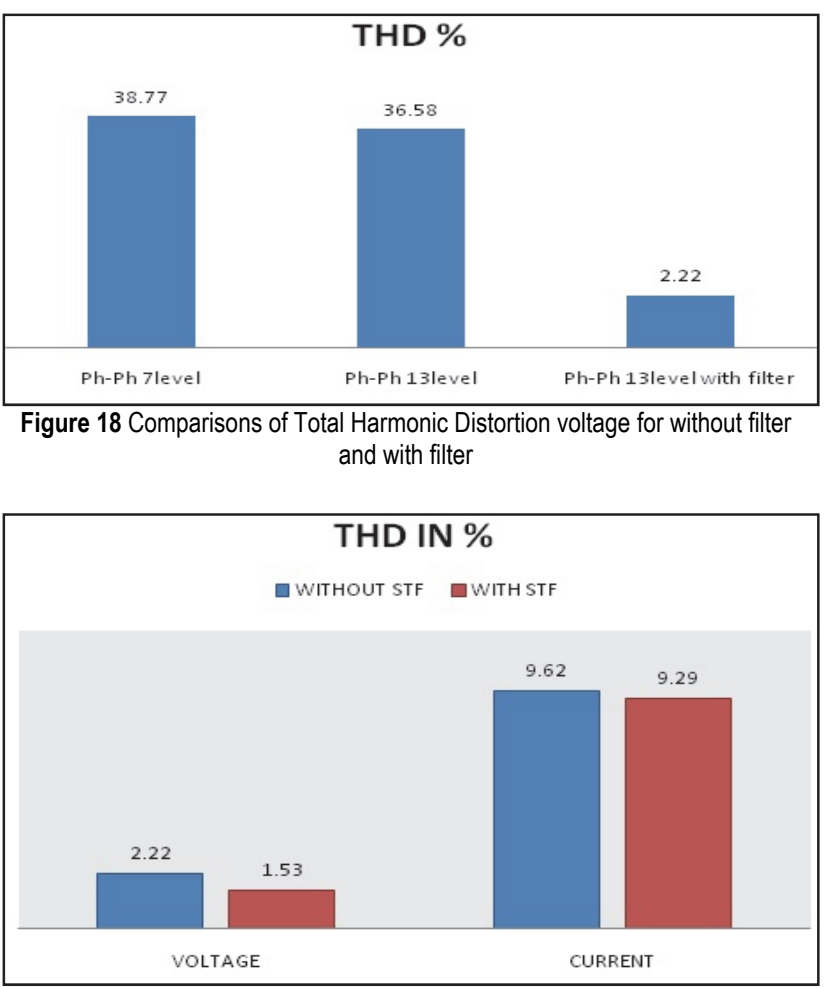

Figure 19 Comparisons of the 13-Level Inverter THD voltage \& current in with and without STF

From Fig. 19 shows that the correlations of THD voltage and current in without self-tuning channel and with self-tuning channel. The all out symphonious twisting (THD) of the heap voltage is $2.22 \%$ (supply voltage without STF) and the heap voltage is $1.53 \%$ (supply voltage with STF). The THD of the heap current is $9.62 \%$ (supply current without STF) and the heap current is 9.29 $\%$ (supply current with STF). It shows 13-level with STF inverter have low consonant twisting.

Table 5 Comparisons between THD in without Self-tuning Filter and with Selftuning Filter

\begin{tabular}{|c|c|c|}
\hline $\begin{array}{c}\text { Total Harmonic } \\
\text { Distortion (THD) }\end{array}$ & $\begin{array}{c}\text { Without Self-tuning } \\
\text { Filter THD } / \%\end{array}$ & $\begin{array}{c}\text { With Self-tuning } \\
\text { Filter THD } / \%\end{array}$ \\
\hline Voltage & 2.22 & 1.53 \\
\hline Current & 9.62 & 9.29 \\
\hline
\end{tabular}

\section{CONCLUSION}

The proposed solar energy-based PMBLDC motor drive using a high step-up modified multi-inverter with a self-tuning filter was analysed and successfully simulated using MATLAB/SIMULINK. We use an MPPT controller with the P\&O algorithm that maximises the solar PV output power. A chopper converter is used to increase the solar voltage level. The multilevel inverter achieved the lowest value of total harmonic distortion (THD) and reduced switching losses. Finally, the THD in the multilevel inverter at various stages were compared. From the comparison, we found that the 13-level inverter with a self-tuning filter had the lowest value. The voltage and current THD was 1.53 and $9.29 \%$, respectively. To maintain the voltage balance between the inverter capacitor and decrease the reactive power. In this PMBLDC motor, using a high step-up modified multilevel inverter, we gained performance, a better system efficiency, and eliminated the harmonics using a self-tuning filter. The hardware implementation of this study and the application of soft computing techniques to improve the performance of the motor will be carried out in the future.

\section{REFERENCES}

[1] Elgendy, M. A., Bashar, Z., \& David, J. A. (2010). Comparison of directly connected and constant voltage controlled photovoltaic pumping systems. IEEE transactions on sustainable energy 1, 3(2010), 184-192.

[2] Benaissa, A., Boualaga, R., \& Ammar, M. (2014). Power quality improvement using fuzzy logic controller for fivelevel shunt active power filter under distorted voltage conditions. Frontiers in Energy 8, 2(2014), 212.

[3] Sathyan, A., et al. (2009). An FPGA-based novel digital PWM control scheme for BLDC motor drives. IEEE transactions on Industrial Electronics 56.8, (2009), 3040-3049. https://doi.org/10.1109/TIE.2009.2022067

[4] Bhim, S. \& Rajan, K. (2016). Simple brushless DC motor drive for solar photovoltaic array fed water pumping system. IET Power Electronics, 9(7). https://doi.org/10.1049/iet-pel.2015.0852

[5] Gupta, G. \& Prerna, G. (2015). Comparative study ofvarious DC-DC converters used in AI-based Solar fed PMBLDC motor drive. India Conference (INDICON), Annual IEEE.

[6] Kazeza, W. H., Chowdhury, S. P., \& Ngoma, L. J. (2015). Optimization of a solar based water pumping system using a high step up inverter. Renewable Power Generation (RPG 2015), International Conference on. IET.

[7] Rajan, K. \& Bhim, S. (2017). Solar PV powered BLDC motor drive for water pumping using Cuk converter. IET Electric Power Applications, 11(2). https://doi.org/10.1049/iet-epa.2016.0328

[8] Rajan, K. \& Bhim, S. (2019). Grid Interactive Solar PV Based Water Pumping Using BLDC Motor Drive. IEEE Transactions on Industry Applications, 55(5). https://doi.org/10.1109/TIA.2019.2928286

[9] Kumar, R. \& Bhim, S. (2014). Buck-boost converter fed BLDC motor drive for solar PV array based water pumping. Power Electronics, Drives and Energy Systems (PEDES), 2014 IEEE International Conference on. IEEE.

[10] Kondawar, S. S. \& Vaidya, U. B. (2012). A comparison of two MPPT techniques for pv system in Matlab simulink. International Journal of Engineering Research and Development 2.7, 73-79.

[11] Gleena, V., Tissa, T., \& Jithin, K. S. (2015). Comparison between conventional and modified cascaded H-bridge multilevel inverter-fed drive. International journal of innovative research in electrical, electronics, instrumentation and control engineering, 3(9).

[12] Ramya, A., Ahamed, I., \& Balaji, M. (2016). Hybrid Self Tuned Fuzzy PID controller for speed control of Brushless DC Motor. Technical Gazette, 57(3). https://doi.org/10.7305/automatika.2017.02.1769

[13] Lokeshwarvuda, C. \& Mithileshverma, M. V. (2014). Modified multilevel inverter with minimum no of switches. International Journal of Advanced Trends in Computer Science and Engineering, 3(1), 411-414.

[14] Julymol, J. \& Arya, P. (2014). Modified cascaded multilevel inverter with GA to reduce line to line voltage THD. International Journal of Electrical Engineering \& Technology (IJEET), 5(12), 32-41.

[15] Singh, V., Gupta, S., Pattnaik, S., \& Tyagi, M. (2015). A new hybrid topology for multilevel inverter for power quality improvement. Power. Communication and Information Technology Conference (PCITC), IEEE.

[16] Sanjeev, S. \& Bhim, S. (2011). Power Quality Improved PMBLDCM Drive for Adjustable Speed Application with Reduced Sensor Buck-Boost PFC Converter. Fourth International Conference on Emerging Trends in Engineering \& Technology, IEEE.

[17] William, C. \& Ramesh, R. Comparative Study of P\&O and InC MPPT Algorithms. American Journal of Engineering 
Research (AJER), e-ISSN: 2320-0847, p-ISSN: 2320-0936 02(12), 402-408.

[18] Anandhi, T. S. \& Prem K. S. (2015). Application of DC-DC Boost Converter for Solar Powered Traffic Light with Battery Backup. Indian Journal of Science and Technology $8(32)$.

[19] Caracas, J. V. M., iet ial. (2012). Implementation of a high efficiency and low cost converter for a photovoltaic water pumping system. Applied Power Electronics Conference and Exposition (APEC), Twenty-Seventh Annual IEEE. IEEE.

[20] Ramya, A., Ahamed, I., \& Balaji, M. (2016). Hybrid Self Tuned Fuzzy PID controller for speed control of Brushless DC Motor. Technical Gazette, 57(3). https://doi.org/10.7305/automatika.2017.02.1769

[21] Kumar, R. \& Bhim, S. (2015). BLDC motor driven water pump fed by solar photovoltaic array using boost converter. India Conference (INDICON), Annual IEEE.

[22] Kumar, R. \& Singh, B. (2014). Buck-boost converter fed BLDC motor drive for solar PV array based water pumping. IEEE Int. Conf. Power Electron. Drives Energy Syst. (PEDES), 1-6.

[23] Singh, B., Bist, V., Chandra, A., \& Al-Haddad, K. (2015). Power factor correction in bridgeless-Luo converter-fed BLDC motor drive. IEEE Trans. Ind. Appl., 51(2), 1179-1188. https://doi.org/10.1109/TIA.2014.2344502

[24] de Brito, M. A. G., Galotto, L., Sampaio, L. P., de Azevedo Melo, G., \& Canesin, C. A. (2013). Evaluation of the main MPPT techniques for photovoltaic applications. IEEE Trans. Ind. Electron., 60(3), 1156-1167.

[25] Ouada, M., Meridjet, M. S., \& Talbi, N. (2013). Optimization photovoltaic pumping system based BLDC using fuzzy logic MPPT control. Int. Renew. Sustain. Energy Conf. (IRSEC), 27-31.

[26] Martin, A. D. \& Vazquez, J. R. (2014)- Back stepping Controller Design to Track Maximum Power in Photovoltaic Systems. Technical Gazette, 55(1),2014 https://doi.org/10.7305/automatika.2014.01.289

\section{Contact information:}

Karuppanasamy CHANDRASEKARAN, M.E, Assistant Professor/EEE

(Corresponding author)

PPG Institute of Technology,

Saravanampatty Post,

Coimbatore-641035

E-mail: samyscv1906@gmail.com

Rajendran ARTHANARI, M.S., Ph.D, Professor/ECE

Karpagam college of Engineering,

Othakalmandabam,

Coimbatore-641032

E-mail: rajendran.a@kce.ac.in 